\title{
BJSM
}

\section{The effect of three different levels of footwear stability on pain outcomes in women runners: a randomised control trial}

Michael B Ryan, Gordon A Valiant, Kymberly McDonald, et al.

Br J Sports Med published online June 27, 2010

doi: 10.1136/bjsm.2009.069849

Updated information and services can be found at:

http://bjsm.bmj.com/content/early/2010/06/26/bjsm.2009.069849.full.html

These include:

References This article cites 28 articles, 10 of which can be accessed free at: http://bjsm.bmj.com/content/early/2010/06/26/bjsm.2009.069849.full.html\#ref-list-1

$\mathbf{P}<\mathbf{P} \quad$ Published online June 27, 2010 in advance of the print journal.

Email alerting Receive free email alerts when new articles cite this article. Sign up in the service box at the top right corner of the online article.

Notes

Advance online articles have been peer reviewed and accepted for publication but have not yet appeared in the paper journal (edited, typeset versions may be posted when available prior to final publication). Advance online articles are citable and establish publication priority; they are indexed by PubMed from initial publication. Citations to Advance online articles must include the digital object identifier (DOIs) and date of initial publication.

To order reprints of this article go to:

http://bjsm.bmj.com/cgi/reprintform

To subscribe to British Journal of Sports Medicine go to:

http://bjsm.bmj.com/subscriptions 


\title{
The effect of three different levels of footwear stability on pain outcomes in women runners: a randomised control trial
}

\author{
Michael B Ryan, ${ }^{1}$ Gordon A Valiant, ${ }^{2}$ Kymberly McDonald, Jack E Taunton ${ }^{1}$
}

1Allan McGavin Sports

Medicine Centre, University of British Columbia, Vancouver,

Canada

${ }^{2}$ Nike Sports Research

Laboratory, Beaverton,

Oregon, USA

\section{Correspondence to} Dr Michael B Ryan, Allan McGavin Sports Medicine Centre, 3055 Wesbrook Mall, University of British Columbia, Vancouver V6T 1Z3, Canada; mryan76@gmail.com

Accepted 10 May 2010

\begin{abstract}
Background The present study examines the injury status in women runners who are randomised to receive a neutral, stability or motion control running shoe. Methods 81 female runners were categorised into three different foot posture types (39 neutral, 30 pronated, 12 highly pronated) and randomly assigned a neutral, stability or motion control running shoe. Runners underwent baseline testing to record training history, as well as leg alignment, before commencing a 13-week half marathon training programme. Outcome measures included number of missed training days due to pain and three visual analogue scale (VAS) items for pain during rest, activities of daily living and with running.
\end{abstract}

Results 194 missed training days were reported by $32 \%$ of the running population with the stability shoe reporting the fewest missed days (51) and the motion control shoe (79) the most. There was a significant main effect $(p<0.001)$ for footwear condition in both the neutral and pronated foot types: the motion control shoe reporting greater levels of pain in all three VAS items. In neutral feet, the neutral shoe reported greater values of pain while running than the stability shoe; in pronated feet, the stability shoe reported greater values of pain while running than the neutral shoe. No significant effects were reported for the highly pronated foot, although this was limited by an inadequate sample size. Conclusion The findings of this study suggest that our current approach of prescribing in-shoe pronation control systems on the basis of foot type is overly simplistic and potentially injurious.

\section{INTRODUCTION}

Running injuries are common in recreational populations, especially for those involved in prolonged training programmes that are greater than 12 weeks in duration. ${ }^{1} 2$ Incidence rates vary depending on sample population and injury definition; however, it is uncommon for less than $30 \%$ of runners to experience an injury that will require time away from sport. ${ }^{2-5}$

Over the last two decades, running footwear has become increasingly stratified in the degree of motion control offered. ${ }^{6}$ Often footwear companies use a subjectively assigned support hierarchy that may resemble the following pattern from less to more support: cushion, neutral supportive, stability, motion control. Such a hierarchy presupposes that high-arched supinating feet are better served in cushioned shoes, markedly overpronating planus foot types should be fit with motion control shoes, and foot types in between set to use either neutral or stability shoes as appropriate.
The effectiveness of running footwear that incorporates stability elements at controlling, or limiting, rearfoot eversion and medial plantar pressure is well documented from both twoand three-dimensional kinematic and pressure distribution analyses. ${ }^{7-11}$ Translational studies integrating the results from these biomechanical investigations into clinically meaningful outcomes have rarely been conducted. In fact, despite over 20 years of stability elements being incorporated in running footwear there is, as yet, no established clinically based evidence for their provision. Only one study conducted on a military population found that there were no differences in injury risk when selected categories of running shoes were assigned based on an individual's foot imprint compared with a control condition (stability shoe). ${ }^{12}$ Motion control running footwear has yet to be proven to prevent running-related injuries. ${ }^{13}$

The objective of the present study is to evaluate prospectively how three stability categories of running footwear are associated with the occurrence of running-related pain in a population of women training for a long-distance running event. Our hypothesis is that the runners wearing shoes that are outside their foot category will experience greater pain than those wearing shoes that they would be conventionally assigned (ie, neutral feet to neutral shoe, pronated feet to stability shoe and highly pronated feet to motion control shoe). Testing of this hypothesis against the null hypothesis of no difference between any of the shoe groups will be performed.

\section{MATERIALS AND METHODS}

A prospective randomised control design approach was used in this study (figure 1).

Ethical approval for this study was obtained from the Clinical Research Ethics Board at the University of British Columbia, and all participants were given full informed consent before taking part. Subjects were recruited primarily through a newspaper advertisement and word of mouth.

All participants were women between the ages of 18 and 50. Volunteers had documented they could run continuously for $60 \mathrm{~min}$ to ensure a minimum preparedness for commencing the training programme and had to have had no history of running injuries or foot orthosis usage within the preceding 6 months. Individuals were excluded if there was a history of surgery to the lower extremity that would have the potential 
to impact their running gait and if there were any known, or suspected, degenerative conditions such as osteoarthritis or chrondromalacia.

During the baseline assessment, a detailed training and injury history was taken, which included information on running experience, previous $10 \mathrm{~km}$, half marathon and marathon best finishing time (if available), an overall number and type of general musculoskeletal and/or running injuries, and previous running shoe make and model. Each subject's Foot Posture Index (FPI) was documented and categorised as neutral, pronated or highly pronated according to the guidelines by Redmond et al. ${ }^{14}$ The FPI has undergone psychometric validation and reliability testing, and has been incorporated in several clinical investigations. ${ }^{15} 16$ The following anthropometric and alignment variables were recorded to test homogeneity between groups of potential confounders based on

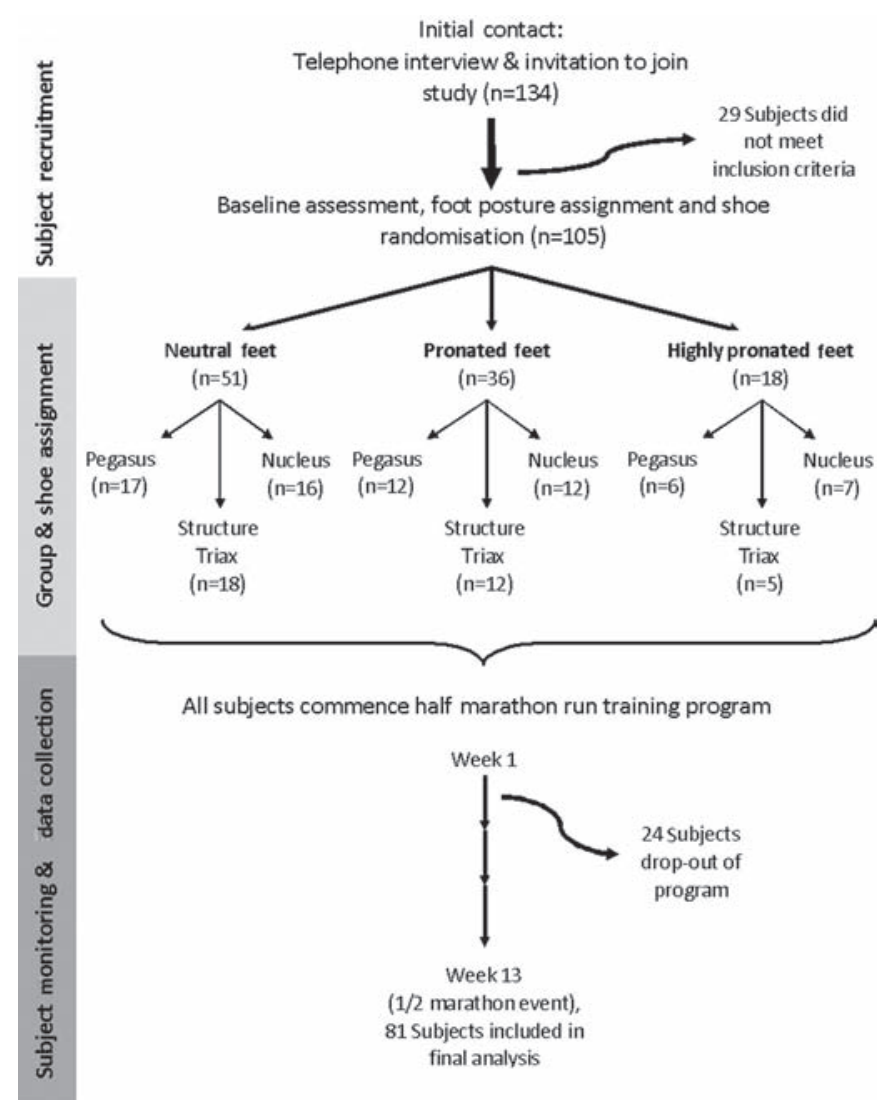

Figure 1 Flow diagram of study design and subject involvement throughout the study process. existing direct or indirect evidence provided in the literature: height, weight, body mass index (BMI), passive Hallux dorsiflexion range of motion ( $R O M)$, quadriceps- or $(\mathrm{Q})$ angle and knee alignment. ${ }^{17-20}$ Hallux ROM was assessed in terms of non-weightbearing using a hand-held goniometer measuring the angle from the line joining the centre of the first metatarsophalangeal (MTP) joint to the centre of the distal first phalanx to the line joining the centre of the first MTP joint to the centre of the calcaneus when the Hallux was passively dorsiflexed to endpoint. The $\mathrm{Q}$-angle was measured with the subject lying supine and reporting the angle formed from the line joining the anterior superior iliac spine to the centre of the patella to the line joining the centre of the patella to the centre of the tibial tuberosity. All assessments were performed by the same observer (MBR) with over 10 years' experience in anthropometric and gait assessments.

Subjects in each foot posture category were then randomly assigned (via a block randomisation scheme-block size 8) to one of three footwear conditions: neutral (Nike Pegasus), stability (Nike Structure Triax) or motion control (Nike Nucleus). Table 1 provides a breakdown of the specific stability elements incorporated into each shoe. A broad description of these shoes as a group is defined by Richards as Pronation Control Elevated Cushioned Heel shoes. ${ }^{13}$ Structural differences between the shoes such as heel elevation, ethyl vinyl acetate durometer, last design, sock-liner support and the weight of the shoes were not measured.

Participants were told to perform all their runs in the shoes provided and were given 1 week to gradually break in the shoes for use with running. If a subject felt that repeated use of a shoe was contributing significantly to pain anywhere in the lower extremity, they were given the option of withdrawing from the study.

Participants in this study underwent a 13 -week run training programme developed by the authors for this study, targeting a half marathon event $(21.1 \mathrm{~km})$ held in Vancouver, BC in June 2009. The programme incorporated three to four run workouts a week, with a longer group run on the weekend and interval training during the middle of the week. The two to three weekday workouts were based on time, while the long run on the weekend was based on distance, in order to accommodate different training paces but ensuring adequate preparation for the $21.1 \mathrm{~km}$ event. The group run was implemented to provide the participants with a positive training environment, and an opportunity to ask questions on their training or other aspects of running in order to optimise compliance. The distance covered during any workout would vary depending on running pace, but it was estimated that the weekly volume started at approximately $20 \mathrm{~km}$ and increased to $40-45 \mathrm{~km}$ at

Table 1 Breakdown of stability elements in each of the three running shoe support categories used in this study: neutral (Pegasus), stability (Structure Triax) and motion control (Nucleus)

\begin{tabular}{llll}
\hline & Neutral (Pegasus) & $\begin{array}{l}\text { Stability } \\
\text { (Structure Triax) }\end{array}$ & Motion control (Nucleus) \\
\hline Heel counter & $*$ & $*$ & $*$ \\
Thermoplastic midfoot shank & $*$ & $*$ & $*$ \\
Posterolateral crash pad & $*$ & $*$ & $*$ \\
Lateral sole flare & $*$ & $*$ & $*$ \\
Thermoplastic buttress & & $*$ & $*$ \\
Dual-density ethyl vinyl acetate midsole & & & $*$ \\
Thermoplastic reinforced dual-density ethyl vinyl & & & $*$ \\
acetate midsole & & &
\end{tabular}


the peak of the programme. There was one rest week (week 5) that assigned $60 \%$ of the previous weeks' run volume, and the programme utilised a 2 -week gradual taper to race day.

Outcome variables used in this study included the number of missed assigned workouts due to running-related pain and visual analogue scale (VAS) items for pain at rest (VASRest), during activities of daily living (VASADL) and during or immediately following running (VASRun). ${ }^{21}$ Subject monitoring was achieved through two ways: (1) by attendance at the weekly group long run and (2) with an online website-based questionnaire to record number of workouts completed that week, reasons for missed workouts (ie, running-related pain, time constraints), the three VAS items and any general comments regarding their run training and/or location of pain.

All data were entered into a personal computer and analysed using PASW statistical software (version 17.0.2; SPSS, Chicago, Illinois). An intention-to-treat analysis approach was used in comparing the effects of one shoe on the others within a given foot posture type to provide a conservative estimate of any effect size. A last value carried forward strategy was used for missing data (due to withdrawals resulting from injury and/or forgoing wearing assigned footwear) in the cases where subjects had reported a minimum of 2 weeks of outcome scores. ${ }^{22}$ Subjects who reported fewer than two follow-up data points were considered drop-outs, and their data were omitted for the purpose of analysis.

For calculating statistical power for subject recruitment, a $20 \%$ difference in the VAS pain scores across groups was considered to be a clinically meaningful difference. Accordingly, assuming an SD of 2.3 in the VAS scores, an $\alpha$ of $5 \%$ and a $\beta$ error level of $10 \%, 12$ subjects were required for each shoe condition within a foot posture subgroup; therefore, 108 subjects was our goal for enrolment. Each foot posture subgroup underwent its own analysis procedure.

Initial comparisons of between-group baseline variables of age, height, weight, BMI, Hallux ROM, Q-angle knee alignment, previous weekly running volume and running experience were compared using one-way analysis-of-variance (ANOVA) tests. A two-way factorial ANOVA was performed to determine whether there were any significant main effects for time and footwear conditions, as well as an interaction effect, for all three VAS item variables. A Fisher least significant difference post-hoc test was used to interpret significant effects from the one-way and twoway ANOVAs. The $\alpha$ value was set at 0.05 for this study.

\section{RESULTS}

After initial interest was expressed from over 130 women, 105 were invited to take part in the study owing to financial constraints limiting the number of shoes that could be provided and after review of eligibility criteria. Twenty-four subjects dropped out of the study after enrolment for the following reasons: inability to commit to programme (18), pregnancy (2), immediate discomfort or poor fit of running shoes (2), death in the family (1) and medical condition during training (gall stones) (1). Data from the remaining 81 participants were included in the analysis whose breakdown per foot posture category may be seen in table 2. Nine subjects within the sample had elected to withdraw from wearing their assigned Nike shoes and returned to their original running footwear (Pegasus $\times 4(1 \times$ neutral; $2 \times$ pronated; $1 \times$ highly pronated $)$; Structure Triax $\times 2(2 \times$ neutral $)$; Nucleus $\times 2(2 \times$ highly pronated)), and three subjects chose to withdraw due to running-related pain (Nucleus $\times 2(2 \times$ highly pronated); Pegasus $\times 1$ (neutral)).

There were significant differences between the shoe categories in the neutral foot posture for weight $(p<0.05)$ and BMI $(p<0.01)$, with the group wearing the Nucleus shoe having greater values than the other two shoe categories. The pronated foot posture group wearing the Nucleus shoe reported having greater running experience $(p<0.05)$. No other significant differences were found for the remaining baseline variables across shoe categories.

One hundred and ninety-four missed training days due to running-related pain were reported by 26 individuals

Table 2 Breakdown of independent variables across shoe conditions within each foot posture category

\begin{tabular}{|c|c|c|c|c|c|c|c|c|}
\hline & $\mathbf{n}$ & Age (years $\pm S D$ ) & Weight (kg \pm SD) & Height $(m \pm S D)$ & BMI (kg/m2) & Run XP (years) & $\begin{array}{l}\text { Run Volume } \\
\text { (h/week) }\end{array}$ & 0-Angle $\left({ }^{\circ}\right)$ \\
\hline \multicolumn{9}{|l|}{ Neutral } \\
\hline Pegasus & 12 & $37 \pm 9$ & $63 \pm 9$ & $166 \pm 6$ & $23 \pm 2$ & $15 \pm 9$ & $19 \pm 8$ & $13 \pm 2$ \\
\hline Structure Triax & 17 & $35 \pm 5$ & $61 \pm 6$ & $167 \pm 7$ & $22 \pm 1$ & $9 \pm 6$ & $26 \pm 9$ & $13 \pm 2$ \\
\hline Nucleus & 10 & $38 \pm 3$ & $70 \pm 12^{*}$ & $167 \pm 5$ & $25 \pm 4^{*}$ & $15 \pm 8$ & $27 \pm 17$ & $15 \pm 4$ \\
\hline \multicolumn{9}{|l|}{ Pronated } \\
\hline Pegasus & 8 & $35 \pm 7$ & $76 \pm 38$ & $164 \pm 6$ & $28 \pm 12$ & $7 \pm 3$ & $25 \pm 12$ & $13 \pm 1$ \\
\hline Structure Triax & 13 & $35 \pm 9$ & $65 \pm 12$ & $164 \pm 5$ & $25 \pm 5$ & $6 \pm 5$ & $26 \pm 15$ & $14 \pm 3$ \\
\hline Nucleus & 9 & $34 \pm 4$ & $60 \pm 7$ & $164 \pm 5$ & $22 \pm 3$ & $11 \pm 5^{*}$ & $17 \pm 11$ & $13 \pm 2$ \\
\hline \multicolumn{9}{|l|}{ Highly pronated } \\
\hline Pegasus & 5 & $27 \pm 3$ & $57 \pm 8$ & $160 \pm 5$ & $22 \pm 2$ & $4 \pm 2$ & $12 \pm 8$ & $14 \pm 3$ \\
\hline Structure Triax & 2 & $26 \pm 2$ & $58 \pm 2$ & $165 \pm 4$ & $22 \pm 2$ & $5 \pm 1$ & $43 \pm 35$ & $16 \pm 1$ \\
\hline Nucleus & 5 & $29 \pm 6$ & $62 \pm 9$ & $163 \pm 5$ & $23 \pm 3$ & $7 \pm 5$ & $14 \pm 8$ & $17 \pm 4$ \\
\hline
\end{tabular}

Values in bold denote a significant difference across shoe categories with the asterisk indicating significant group differences after post-hoc analysis.

Table 3 Percentage of runners (with absolute number in parentheses) reporting a missed training day due to running-related pain for each footwear condition across foot posture type

\begin{tabular}{llll}
\hline & Neutral & Pronated & Highly pronated \\
\hline Neutral (Pegasus) & $33.3 \%(n=4)$ & $25.0 \%(n=2)$ & $40.0 \%(n=2)$ \\
Stability (Structure Triax) & $11.8 \%(n=2)$ & $23.1 \%(n=3)$ & $0.0 \%(n=0)$ \\
Motion control (Nucleus) & $40.0 \%(n=4)$ & $44.4 \%(n=4)$ & $100.0 \%(n=5)$ \\
\hline
\end{tabular}


throughout the 13 -week training period, amounting to $32 \%$ of the study cohort reporting running-related pain (tables 3, 4).

After carrying out the two-way ANOVA, there were several significant main effects, which will be described per foot posture subgroup. There was a significant main effect $(p<0.001)$ for footwear condition for all VAS items for the neutral feet, with participants wearing the motion control shoe having significantly greater pain than either the stability or neutral shoe for all three VAS items (figures 2-4; table 5). Additionally, for VASRun, participants wearing the neutral shoe reported greater overall pain than participants wearing the stability shoe.

For the pronated foot posture, there was a significant main effect for footwear condition for all VAS items. For all three VAS items, participants wearing the motion control shoe had greater pain throughout the 13-week training period than participants wearing the neutral and stability shoes (figures 5-7).
For VASRun, participants wearing the stability shoe had greater pain than the neutral shoe (figure 7).

There were no significant main or interaction effects reported for the highly pronated foot posture.

\section{DISCUSSION}

The objective of this study was to observe the injury and running-related pain patterns in a population of runners who were randomly given a neutral, stability or motion control shoe regardless of foot type classification. To the best of the authors' knowledge, no previous study has investigated this research question in a similar practical setting.

A half-marathon distance was chosen as the target event to ensure adequate exposure to weekly training volume and any potential effect of footwear on the injury or pain occurrence. We reported $32 \%$ of participants experiencing missed training days due to pain, which, if considered as a rate of injury

Table 4 Frequency and location of running-related pain causing missed training days experienced during the 13-week running programme for shoe category by foot posture

\begin{tabular}{|c|c|c|c|c|}
\hline & Neutral & Pronated & Highly pronated & Total \\
\hline Neutral (Pegasus) & $\begin{array}{l}\text { Groin: } 6 \\
\text { Knee: } 38 \\
\text { Dorsal foot: } 2 \\
\text { Hamstring: } 1 \\
\text { Unknown: } 2 \\
\text { Total: } 49(n=4)\end{array}$ & $\begin{array}{l}\text { Plantar foot (arch): } 7 \\
\text { Iliotibial band: } 5 \\
\text { Total: } 12(n=2)\end{array}$ & $\begin{array}{l}\text { Plantar foot (arch): } 2 \\
\text { Knee: } 1 \\
\text { Total: } 3(n=2)\end{array}$ & $64(n=8)$ \\
\hline Stability (Structure Triax) & $\begin{array}{l}\text { Knee: } 33 \\
\text { Hamstring: } 3 \\
\text { Anterior lower leg: } 1 \\
\text { Unknown: } 1 \\
\text { Total: } 38(n=2)\end{array}$ & $\begin{array}{l}\text { Knee: } 4 \\
\text { Plantar foot (arch): } 4 \\
\text { Calf: } 3 \\
\text { Anterior lower leg: } 2 \\
\text { Total: } 13(n=3)\end{array}$ & Total: $0(n=0)$ & $51(n=5)$ \\
\hline Motion control (Nucleus) & $\begin{array}{l}\text { Hamstring: } 13 \\
\text { Knee: } 6 \\
\text { lliotibial band: } 5 \\
\text { Forefoot: } 1 \\
\text { Unknown: } 2 \\
\text { Total: } 27(n=4)\end{array}$ & $\begin{array}{l}\text { Knee: } 4 \\
\text { Ankle: } 2 \\
\text { Anterior lower leg: } 1 \\
\text { Hip: } 1 \\
\text { Unknown: } 1 \\
\text { Total: } 9(n=4)\end{array}$ & $\begin{array}{l}\text { Anterior lower leg: } 21 \\
\text { Knee: } 15 \\
\text { Foot (unspecified): } 4 \\
\text { Calf: } 3 \\
\text { Total: } 43(n=5)\end{array}$ & $79(n=13)$ \\
\hline Total & $114(n=10)$ & $34(n=9)$ & $46(n=7)$ & $194(n=26)$ \\
\hline
\end{tabular}

The number of runners reporting missed training days due to running-related pain for each subgroup is in parentheses.

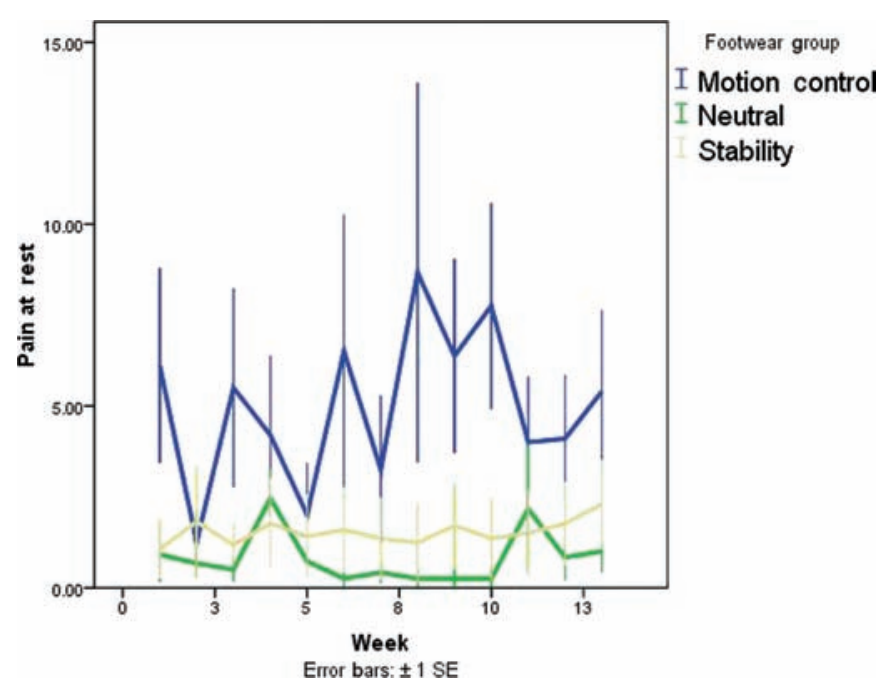

Figure 2 Graph illustrating pain at rest in runners with a neutral foot posture across shoe categories. Note the significantly higher pain levels throughout the training period in the participants wearing the motion control shoes (main effect for shoe).

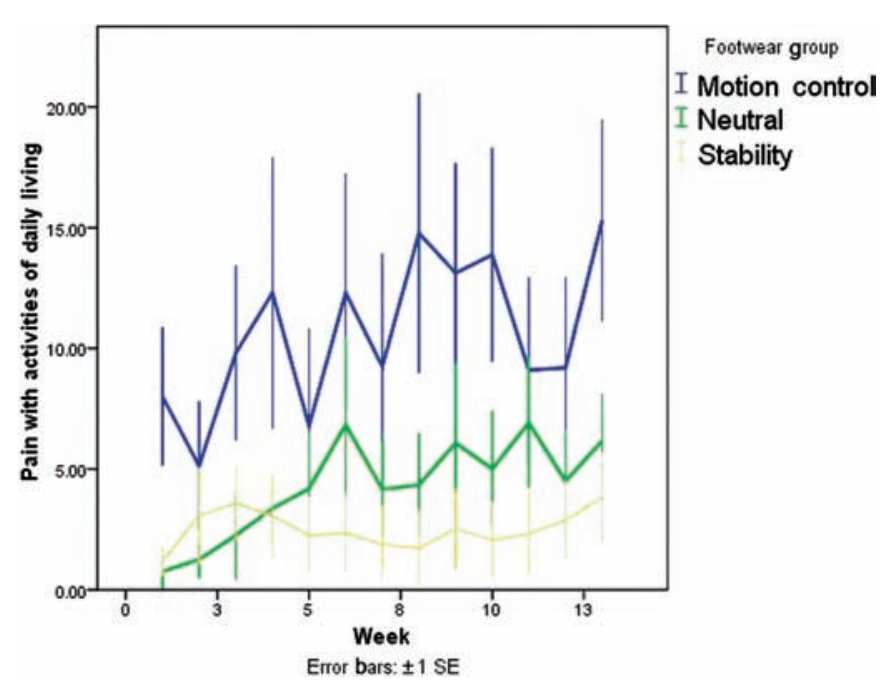

Figure 3 Graph illustrating pain with activities of daily living in runners with a neutral foot posture across shoe categories. Note the significantly higher pain levels throughout the training period in the participants wearing the motion control shoes (main effect for shoe). 
Table 5 Summary of mean visual analogue scores (VAS) ( \pm SD) for shoe category by foot posture

\begin{tabular}{|c|c|c|c|c|c|c|c|c|c|}
\hline & \multicolumn{3}{|l|}{ Neutral } & \multicolumn{3}{|l|}{ Pronated } & \multicolumn{3}{|c|}{ Highly pronated } \\
\hline & VASRest & VASADL & VASRun & VASRest & VASADL & VASRun & VASRest & VASADL & VASRun \\
\hline Neutral (Pegasus) & $0.8 \pm 2.3$ & $4.3 \pm 7.7$ & $12.5 \pm 20 t$ & $4.1 \pm 9.4$ & $2.9 \pm 6.6$ & $5.6 \pm 11.3$ & $5.4 \pm 11.8$ & $7.3 \pm 14.1$ & $10.5 \pm 10.7$ \\
\hline Motion control (Nucleus) & $5.1 \pm 8.0 *$ & $10.7 \pm 12.8^{*}$ & $15.3 \pm 19.1^{*}$ & $11.1 \pm 27.1 *$ & $12.6 \pm 25.6 *$ & $19.0 \pm 28.7^{*}$ & $7.9 \pm 12.6$ & $11.6 \pm 17.3$ & $17.1 \pm 21.0$ \\
\hline
\end{tabular}

Numbers in bold indicate a significant difference across shoe categories.

* Significance between motion control shoe and both the other footwear conditions.

tSignificance between the neutral shoe and the stability shoe only.

$A D L$, activities of daily living.

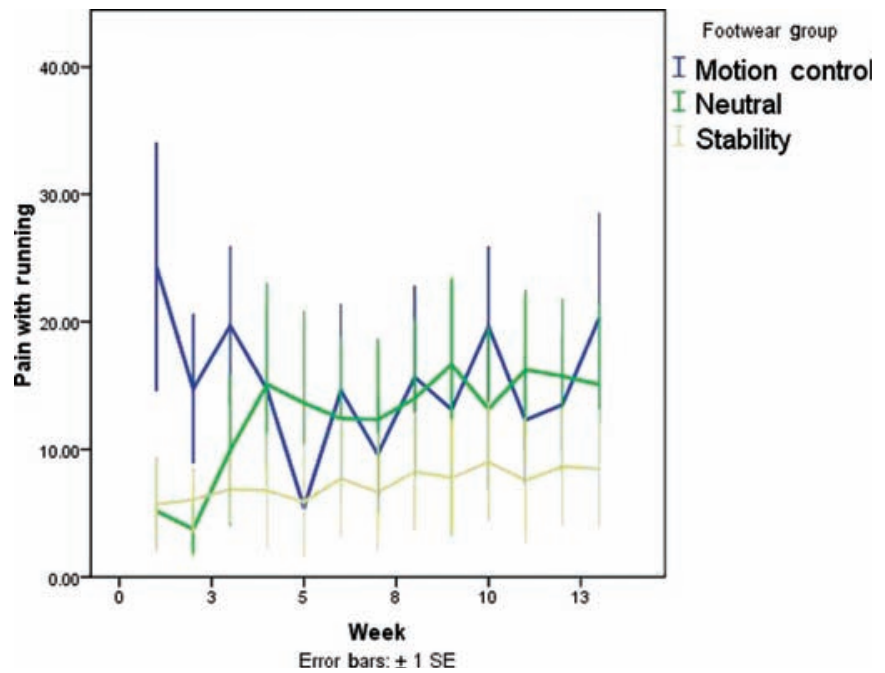

Figure 4 Graph illustrating pain associated with running in runners with a neutral foot posture across shoe categories. There were significantly higher pain levels throughout the training period in the participants wearing the motion control shoes and the lower pain levels in the runners wearing the stability runners.

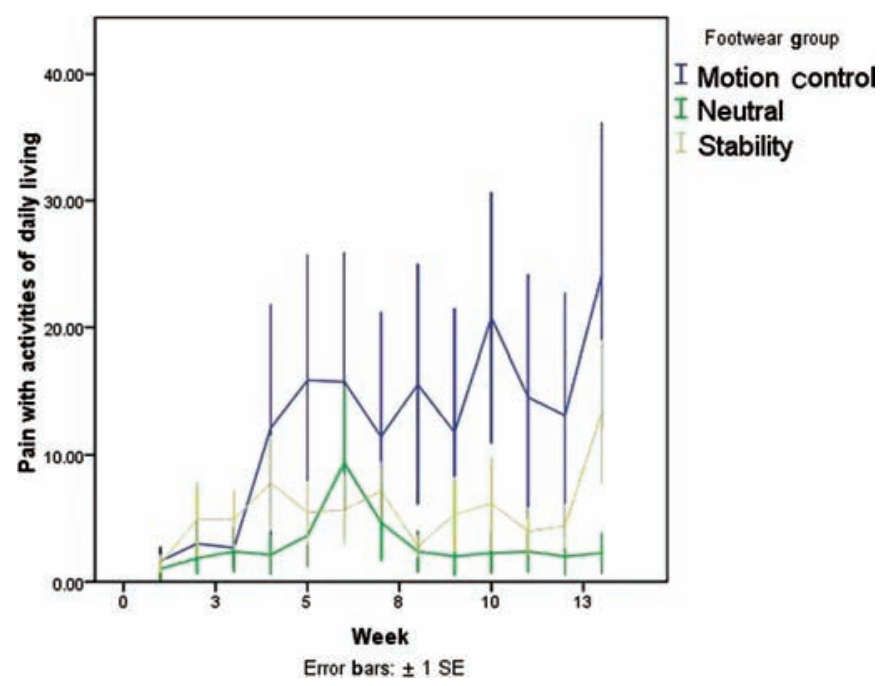

Figure 6 Graph illustrating pain with activities of daily living in runners with a pronated foot posture across shoe categories. Note the significantly higher pain levels throughout the training period in the participants wearing the motion control shoes (main effect for shoe).

incidence, is in line with other prospective incidence studies on running injuries. ${ }^{2-4} 23$

The motion control shoe used in this study resulted in both a greater number of injured runners and missed training days

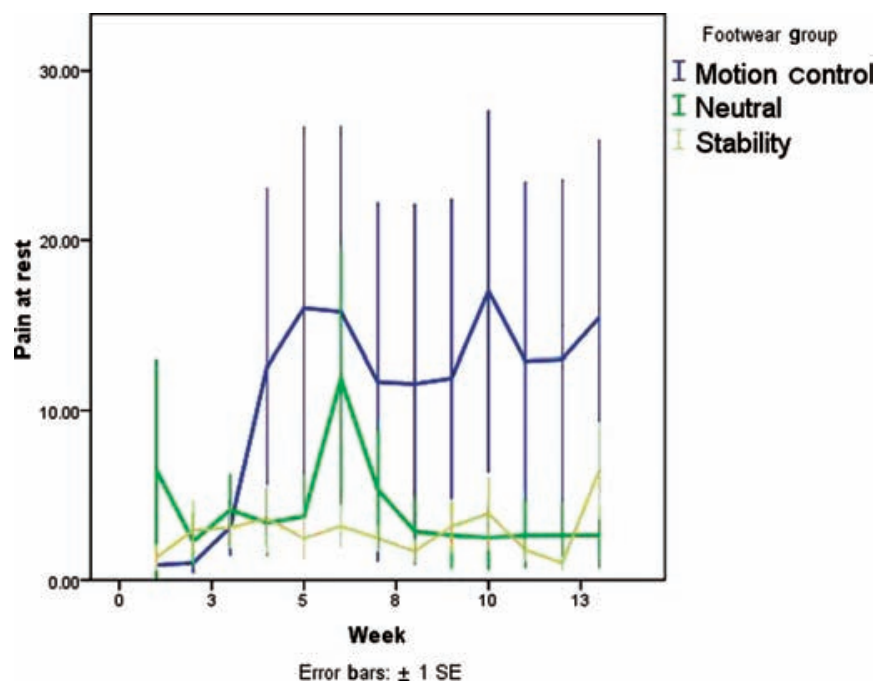

Figure 5 Graph illustrating pain at rest in runners with a pronated foot posture across shoe categories. Note the significantly higher pain levels throughout the training period in the participants wearing the motion control shoes (main effect for shoe).

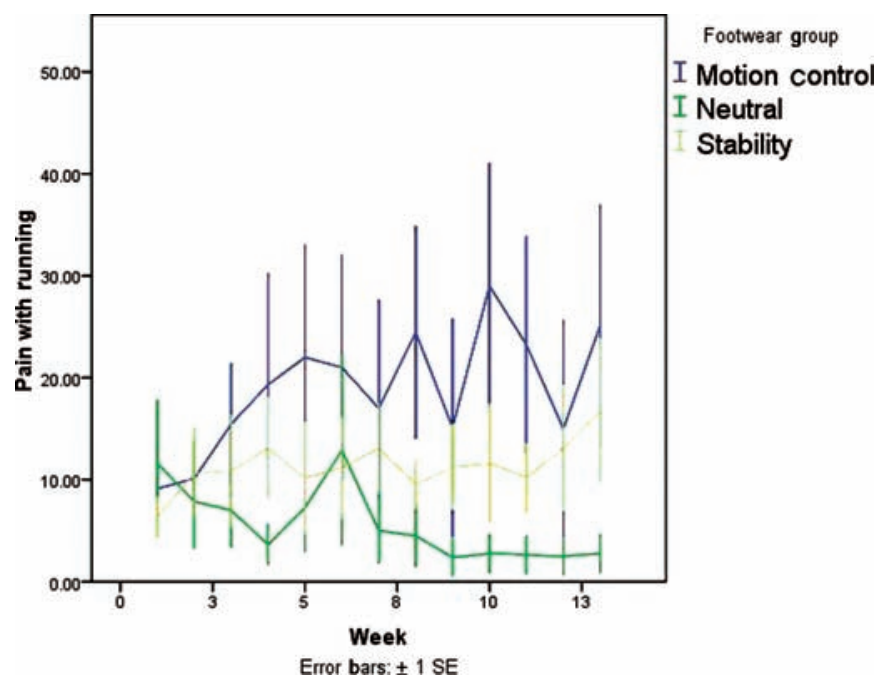

Figure 7 Graph illustrating pain associated with running in runners with a pronated foot posture across shoe categories. Note there were significantly higher pain levels throughout the training period in the participants wearing the motion control shoes and the lower pain levels in the runners wearing the neutral runners.

than the other two shoe categories. Although the sample size is small in the highly pronated group, it is noteworthy that every runner who trained in the motion control shoe with a highly pronated foot posture reported an injury, compared 
with only two of the runners in this same foot posture category wearing the neutral shoe (table 3 ).

These outcomes are remarkable on two levels based on our current conventions of running shoe prescription: (1) that there would be more missed training days due to pain reported with a shoe that was worn by its intended (theoretical) foot posture (excessive pronators and motion control shoe; neutral feet and neutral shoes) and (2) that there were relatively few missed training days due to pain when the highly pronated runners wore a shoe that had the least number of stability elements (Pegasus). These results concerning missed workouts should be interpreted with caution, as the reporting scheme may be particularly sensitive to more severe injuries, thus requiring more missed workouts, which by definition in this study would count a high number of missed training days due to pain for a given foot posture subgroup when only small number of individuals experienced an injury of relatively greater severity.

For the runners classified as having a neutral foot posture, there were greater levels of pain reported by those wearing the motion control shoe throughout the duration of the 13-week training period (main effect for shoe). However, the neutral shoe resulted in greater levels of pain with running than the stability shoe. These results imply that a certain degree of additional stability may be beneficial for those individuals with a neutral foot posture, but too much support may be detrimental.

It is worth considering whether the reported statistical differences are also clinically significant (or relevant). From a quantitative standpoint examining the absolute difference in the VAS values across groups (table 5), the difference in VAS items between the motion control shoe and the two other shoe categories ranges from 3.6 to 13.4; the difference between the neutral and stability shoes ranges from 5.2 to 5.8. As previous groups have identified a minimum clinically significant difference with similar 100 point VAS questionnaires to vary between 9 and 12 points, only the differences between the motion control shoe and neutral shoe for the pronated foot type would qualify as clinically meaningful. ${ }^{24} 25$ That said, the reported differences in pain across footwear groups in the neutral and pronated feet appear to correspond with the number of runners in these respective groups reporting an missed training days due to pain.

Based on data from missed training days due to pain and pain level outcomes from the present study, our hypothesis was disproved such that conventional assignment of footwear stability categories did not result in the least amount of pain per foot posture type. There could be several reasons for this disparity. The conventional assignment of footwear to foot posture types appears dictated more by estimations of control needed rather than by empirically derived footwear assignment algorithms. This fact itself may be a victim of the paucity of valid, reliable and practical foot posture assessment tools available in the 1980s and 1990s, when many of the stability elements were being integrated into running shoes; therefore the indications for a feature such as dualdensity midsoles were far more arbitrarily, rather than clinically, assigned.

The only other investigation to study the effect of different levels of footwear stability on the incidence of injury was conducted by Knapik et al; however, there are considerable differences between this study and the present investigation which interfere with a direct comparison of results. ${ }^{12}$ Of particular note, Knapik's study uses a military population participating in basic training, and the assignment of shoes was not randomised across foot types; rather, assigned shoes in their experimental group was based on plantar foot shape only.

Limitations with the present study include a relatively low sample size resulting in reduced statistical power for some of the comparisons, in particular regarding the highly pronated foot type. There was not complete homogeneity across all shoe category groups in the neutral and pronated foot posture subgroups. Specifically, the group wearing the motion control shoe was significantly heavier, and heavier relative to body height, than the other two shoe category groups representing a potential confounding factor. Body weight and BMI have been implicated as causative for running injuries by various authors with their direct effect on the occurrence of plantar fasciitis, tibial stress fractures and spinal injuries previously reported. ${ }^{182627}$ The pronated foot posture group wearing the Nucleus was documented as having greater running experience, which may be less of a confounder, considering that it has previously been reported as a protective factor for injury. ${ }^{28}$ Differences with respect to training pace could have resulted in absolute weekly training volume differences between groups-a strong confounder for injury risk. ${ }^{29}$ As no betweengroup differences were found for training pace or personal best running event completion times, it is unlikely that differences in training pace between groups influenced these results. Monitoring of additional confounders such as cross-training, races undertaken, medical illness or performance enhancing drug use during the training period was not performed. No independent healthcare professionals assessed each running injury, which weakens the validity of any reported injury.

In conclusion, results from the present study provide evidence that the provision of motion control shoes to neutral or pronated foot types carries a significant risk of experiencing running-related pain in women training for a half marathon. Based on the number of missed training days due to pain and self-reported pain with running, neutral runners may be best served wearing a stability shoe. This study is unable to provide support for the convention that highly pronated runners should wear motion control shoes. Current conventions for assigning stability categories for women's running shoes do not appear appropriate based on the risk of experiencing pain when training for a half marathon.

Acknowledgements The authors wish to express their gratitude to P Moore, for both the use of his retail store and his insights on administering quality run-training clinics. The authors would also like to acknowledge both Nike Canada, for donating clothing to our clinic leaders, and Nike Global, for providing footwear and funding for this project.

Funding Nike Global, One Bowerman Drive, Beaverton, Oregon, USA.

Competing interests A research partnership grant from Nike Global was awarded to MBR, JET and KM to conduct this investigation. GAV is employed at Nike Global

Patient consent Obtained.

Ethics approval Ethics approval was provided by the Clinical Research Ethics Board at the University of British Columbia.

Provenance and peer review Not commissioned; externally peer reviewed.

\section{REFERENCES}

1. Bovens AM, Janssen GM, Vermeer HG, et al. Occurrence of running injuries in adults following a supervised training program. Int J Sports Med 1989;10(Suppl 3):S186-90.

2. Marti B, Vader JP, Minder CE, et al. On the epidemiology of running injuries. The 1984 Bern Grand-Prix study. Am J Sports Med 1988;16:285-94.

3. Jacobs SJ, Berson BL. Injuries to runners: a study of entrants to a 10,000 meter race. Am J Sports Med 1986;14:151-5.

4. Taunton JE, Ryan MB, Clement DB, et al. A prospective study of running injuries: the Vancouver Sun Run 'In Training' clinics. Br J Sports Med 2003;37:239-44. 
5. Walter SD, Hart LE, Mclntosh JM, et al. The Ontario cohort study of runningrelated injuries. Arch Intern Med 1989;149:2561-4.

6. McKenzie DC, Clement DB, Taunton JE. Running shoes, orthotics, and injuries. Sports Med 1985;2:334-47.

7. Butler RJ, Davis IS, Hamill J. Interaction of arch type and footwear on running mechanics. Am J Sports Med 2006;34:1998-2005.

8. Butler RJ, Hamill J, Davis I. Effect of footwear on high and low arched runners' mechanics during a prolonged run. Gait Posture 2007;26:219-25.

9. Cheung RT, Ng GY. Influence of different footwear on force of landing during running. Phys Ther 2008;88:620-8.

10. Clarke TE, Frederick EC, Hamill CL. The effects of shoe design parameters on rearfoot control in running. Med Sci Sports Exerc 1983;15:376-81.

11. Stacoff A, Kälin X, Stüssi E. The effects of shoes on the torsion and rearfoot motion in running. Med Sci Sports Exerc 1991;23:482-90.

12. Knapik JJ, Swedler DI, Grier TL, et al. Injury reduction effectiveness of selecting running shoes based on plantar shape. J Strength Cond Res 2009;23:685-97.

13. Richards CE, Magin PJ, Callister R. Is your prescription of distance running shoes evidence-based? Br J Sports Med 2009;43:159-62.

14. Redmond AC, Crosbie J, Ouvrier RA. Development and validation of a novel rating system for scoring standing foot posture: the Foot Posture Index. Clin Biomech (Bristol, Avon) 2006;21:89-98.

15. Keenan AM, Redmond AC, Horton M, et al. The Foot Posture Index: Rasch analysis of a novel, foot-specific outcome measure. Arch Phys Med Rehabil 2007;88:88-93

16. Redmond AC, Crane YZ, Menz HB. Normative values for the Foot Posture Index. $J$ Foot Ankle Res 2008;1:6.

17. Rauh MJ, Koepsell TD, Rivara FP, et al. Quadriceps angle and risk of injury among high school cross-country runners. J Orthop Sports Phys Ther 2007; 37:725-33.
18. Taunton JE, Ryan MB, Clement DB, et al. A retrospective case-control analysis of 2002 running injuries. Br J Sports Med 2002;36:95-101.

19. Wen DY, Puffer JC, Schmalzried TP. Injuries in runners: a prospective study of alignment. Clin J Sport Med 1998;8:187-94.

20. Lun V, Meeuwisse WH, Stergiou P, et al. Relation between running injury and static lower limb alignment in recreational runners. Br J Sports Med 2004;38:576-80.

21. Wewers ME, Lowe NK. A critical review of visual analogue scales in the measurement of clinical phenomena. Res Nurs Health 1990;13:227-36.

22. Pledger G. Compliance in clinical trials: impact on design, analysis and interpretation. In: Schmidt D, Leppik I, eds. Compliance in epilepsy. Amsterdam: Elsevier Science Publishers, 1988:125-33.

23. Brunet ME, Cook SD, Brinker MR, et al. A survey of running injuries in $1505 \mathrm{com}-$ petitive and recreational runners. J Sports Med Phys Fitness 1990:30:307-15.

24. Kelly AM. Does the clinically significant difference in visual analog scale pain scores vary with gender, age, or cause of pain? Acad Emerg Med 1998;5:1086-90.

25. Kelly $\mathbf{A M}$. The minimum clinically significant difference in visual analogue scale pain score does not differ with severity of pain. Emerg Med J 2001;18:205-7.

26. Heir T, Eide G. Age, body composition, aerobic fitness and health condition as risk factors for musculoskeletal injuries in conscripts. Scand J Med Sci Sports 1996;6:222-7.

27. Messier SP, Legault C, Schoenlank CR, et al. Risk factors and mechanisms of knee injury in runners. Med Sci Sports Exerc 2008;40:1873-9.

28. van Mechelen W. Running injuries. A review of the epidemiological literature. Sports Med 1992;14:320-35.

29. Ryan M, MacLean C, Taunton JE. A review of anthropometric, biomechanical, neuromuscular and training related factors associated with injury in runners. International Sportmed Journal 2006;7:120-37. 